\title{
Ceftolozane/Tazobactam for Treating Children With Exacerbations of Cystic Fibrosis Due to Pseudomonas aeruginosa: A Review of Available Data
}

\section{OPEN ACCESS}

Edited by:

Manuela Zlamy,

Innsbruck Medical University, Austria

Reviewed by:

Katrin Anne Becker,

University of

Duisburg-Essen, Germany

Danilo Buonsenso,

Catholic University of the Sacred

Heart, Italy

*Correspondence:

Silvia Garazzino

silvia.garazzino@unito.it

Specialty section:

This article was submitted to

Pediatric Infectious Diseases,

a section of the journal

Frontiers in Pediatrics

Received: 07 February 2020

Accepted: 26 March 2020

Published: 05 May 2020

Citation:

Garazzino S, Altieri E, Silvestro E,

Pruccoli G, Scolfaro $C$ and

Bignamini E (2020)

Ceftolozane/Tazobactam for Treating

Children With Exacerbations of Cystic

Fibrosis Due to Pseudomonas

aeruginosa: A Review of Available

Data. Front. Pediatr. 8:173.

doi: 10.3389/fped.2020.00173

\author{
Silvia Garazzino ${ }^{1 *}$, Elena Altieri ${ }^{1}$, Erika Silvestro ${ }^{1}$, Giulia Pruccoli $^{2}$, Carlo Scolfaro ${ }^{1}$ and \\ Elisabetta Bignamini ${ }^{3}$
}

${ }^{1}$ Department of Child Pathology and Treatment "Regina Margherita", Unit of Infectious Diseases, University of Turin, Città della Salute e della Scienza di Torino, Turin, Italy, ${ }^{2}$ Postgraduate School of Pediatrics, University of Turin, Turin, Italy, ${ }^{3}$ Division of Pulmonology, Pediatric Cystic Fibrosis Centre, Città della Salute e della Scienza di Torino, Turin, Italy

Ceftolozane-tazobactam is a novel fifth-generation cephalosporin/ $\beta$-lactamase inhibitor combination recently approved for treatment of both complicated intra-abdominal and urinary tract infections in adults. Considering its potent bactericidal activity against Pseudomonas aeruginosa, it might represent an important option also for treating children with exacerbations of cystic fibrosis due to Pseudomonas aeruginosa when other alternative treatments have been exhausted. We hereby review available data on the use of ceftolozane-tazobactam in children, focusing on cystic fibrosis.

Keywords: Ceftolozane/tazobactam (C/T), cystic fibrosis-CF, children, pulmonary exacerbation, Pseudomonas aeruginosa

\section{INTRODUCTION}

Pseudomonas aeruginosa is the leading cause of acute respiratory exacerbations in patients affected by cystic fibrosis (CF), both adults and children. Chronic infections are related with a progressive decline in pulmonary function; consequently, aggressive antimicrobial treatment of exacerbations is essential to improve expectancy and quality of life, especially in patients awaiting lung transplantation (1). However, with the widespread of multidrug-resistant (MDR) strains, the choice of an appropriate antimicrobial treatment is becoming more difficult, especially in the pediatric setting, where the new available drugs are often off-label in terms of age, indication, and dosage.

Ceftolozane-tazobactam (C/T) is a novel fifth-generation cephalosporin/ $\beta$-lactamase inhibitor combination with activity against MDR Gram-negative bacilli that has been approved by the Food and Drug Administration and the European Medicines Agency for treatment of complicated intra-abdominal infections (cIAIs), complicated urinary tract infections (cUTIs), pyelonephritis, and hospital-acquired pneumonia (HAP) in adult patients. Ceftolozane-tazobactam has been successfully used for treating acute pulmonary CF exacerbations in adults, although not licensed for such indication $(2,3)$. Because of its spectrum of activity, C/T might represent an important option also for $\mathrm{CF}$ children with $P$. aeruginosa infections when other alternative treatments have been exhausted.

To date, the clinical experience with the use of $\mathrm{C} / \mathrm{T}$ in children is extremely limited, dosing data are scanty, and only a few of the agreed Pediatric Investigation Plans have been completed (4). 
We hereby review the available data on the use of $\mathrm{C} / \mathrm{T}$ in children, focusing on CF patients.

\section{MECHANISM OF ACTION AND MICROBIOLOGIC DATA}

Ceftolozane belongs to the class of cephalosporins and is structurally similar to ceftazidime, but it has a modified 3position pyrazole side chain that increases its activity against $P$. aeruginosa. Its potent bactericidal activity relies upon inhibition of bacterial cell-wall synthesis through inhibition of penicillinbinding proteins (PBPs); compared to ceftazidime, ceftolozane displays a higher affinity for the P. aeruginosa PBPs $1 \mathrm{~b}, 1 \mathrm{c}$, and 3 and has an increased stability to AmpC $\beta$-mediated resistance, which is common among $P$. aeruginosa strains $(5,6)$.

Tazobactam is a potent, irreversible inhibitor of most class A and some class C $\beta$-lactamases, which broadens ceftolozane's activity to most extended-spectrum $\beta$-lactamase (ESBL)-producing Gram-negative bacteria and confers some anaerobic activity $(7,8)$.

The fixed dose combination currently available with a 2:1 ratio of ceftolozane and tazobactam comes from studies comparing the efficacy of different ratio combinations (2:1, 4:1, and 8:1), in which the 2:1 appeared the most potent (9).

The strong activity of ceftolozane alone and of $\mathrm{C} / \mathrm{T}$ against $\beta$ lactam-resistant (including meropenem-resistant) $P$. aeruginosa has been widely documented in non-CF strains isolated from adults and children, showing a superiority of $\mathrm{C} / \mathrm{T}$ in comparison to ceftazidime-avibactam (CZA) in terms of susceptibility in vitro $(10-15)$. In the study by Humphries et al. (16), more than onethird (36\%) of CZA-resistant isolates resulted C/T susceptible, whereas only $9 \% \mathrm{C} / \mathrm{T}$-resistant isolates were still CZA susceptible.

In an Italian nationwide survey on $P$. aeruginosa isolated from invasive infections, $\mathrm{C} / \mathrm{T}$ appeared the most active molecule, retaining activity against $90.9 \%$ of isolates, followed by amikacin (88.0\% susceptibility) and colistin (84.7\% susceptibility) (17).

Also according to a global surveillance program including isolates from inpatients in four continents, including children, $\mathrm{C} / \mathrm{T}$ displays the highest activity against $P$. aeruginosa among the currently available drugs except for colistin $(12,13)$.

Resistance to $\mathrm{C} / \mathrm{T}$ may be driven by different mechanisms, such as OprD membrane protein loss or downregulation, overexpression of AmpC $\beta$-lactamase, or overexpression of efflux pumps (17-21).

It must be considered that the characteristics of bacteria isolated from $\mathrm{CF}$ patients differ from those found in the general population. Indeed, in the respiratory tract of $\mathrm{CF}$ patients, where bacterial eradication is hardly attainable once

\footnotetext{
Abbreviations: C/T, ceftolozane-tazobactam; CF, cystic fibrosis; cIAI, complicated intra-abdominal infection; cUTI, complicated urinary tract infection; CZA, ceftazidime-avibactam; ESBL, extended-spectrum $\beta$-lactamase; fT $>$ MIC, free time above the MIC; HABP, hospital-acquired bacterial pneumonia; HAP, hospital-acquired pneumonia; IV, intravenous; MIC, minimal inhibitory concentration; MDR, multidrug-resistant; PBPs, penicillin-binding proteins; PD, pharmacodynamic; PDR, pan-drug resistant; PK, pharmacokinetic; PopPK, population PK; Q8h, every $8 \mathrm{~h}$ (quaque $8 \mathrm{~h}$ ); RTI, respiratory tract infection; VABP, ventilator-associated bacterial pneumonia; XDR, extensively drug-resistant.
}

colonization has been established, mucoid, and hypermutable $P$. aeruginosa strains are highly relevant. Several studies on $P$. aeruginosa isolates from patients with $\mathrm{CF}$ are available, showing a potent, concentration-independent bactericidal activity of C/T also on mucoid and resistant isolates, although percentages of susceptibility to $\mathrm{C} / \mathrm{T}$ are on average lower than those reported in non-CF strains $(10,22-24)$.

No relevant activity of $\mathrm{C} / \mathrm{T}$ against Burkholderia cepacia has been reported (23).

In one of the first studies on MDR $P$. aeruginosa isolates from $\mathrm{CF}$ adults, ceftolozane resulted the most active among tested drugs, although up to $36 \%$ of the isolates had a minimal inhibitory concentration (MIC) of $>8 \mu \mathrm{g} / \mathrm{mL}$ (23).

Gramegna et al. (25) analyzed a panel of $120 \quad P$. aeruginosa isolates from CF adult patients, including $42.5 \%$ of MDR/extensively drug-resistant (XDR) strains and $2.5 \%$ of pan-drug-resistant (PDR) strains. Within the $\beta$-lactams tested, $\mathrm{C} / \mathrm{T}$ had the lowest percentage of in vitro antimicrobial resistance against $P$. aeruginosa: $84.2 \%$ isolates were susceptible to $\mathrm{C} / \mathrm{T}$, and only two were highly resistant (MIC $>256 \mathrm{mg} / \mathrm{mL}$ ). The $\mathrm{MIC}_{50}$ and $\mathrm{MIC}_{90}$ values for $\mathrm{C} / \mathrm{T}$ against $P$. aeruginos a were 1.5 and $8 \mathrm{mg} / \mathrm{mL}$, respectively. Ceftolozane-tazobactam appeared effective in most of the meropenem-resistant $P$. aeruginosa strains (25).

In a smaller sample of XDR and PDR $P$. aeruginosa also collected from adult CF patients, C/T showed the highest percentage of in vitro susceptibility ( 30 vs. $<10 \%$ of other antibiotics tested). Considering only XDR isolates, susceptibility to $\mathrm{C} / \mathrm{T}$ was reported in $43 \%$ of cases. None of the nine PDR strains were susceptible to $\mathrm{C} / \mathrm{T}$, although two had intermediate MICs (26).

In a more recent study, the in vitro activity of $\mathrm{C} / \mathrm{T}$ against $P$. aeruginosa in CF patients was comparable to colistin (susceptibility rate 85.1 vs. $89.4 \%$ ) but significantly higher than other antimicrobials (27). Ceftolozane-tazobactam was active against $70,58.1$, and $100 \%$ of MDR, XDR, and PDR strains, respectively. No differences in $\mathrm{C} / \mathrm{T}$ activity were observed between isolates from children and adult patients, except for XDR ones that resulted significantly more susceptible in older patients. Activity of $\mathrm{C} / \mathrm{T}$ toward mucoid isolates was inferior to colistin (82.9 vs. $97.6 \%$ ) but higher compared with other antibiotics.

To our knowledge, only two further studies evaluated the in vitro activity of $\mathrm{C} / \mathrm{T}$ on $P$. aeruginosa strains that were isolated from children affected by Kuti et al. (28) tested $\mathrm{C} / \mathrm{T}$ on 50 non-duplicate MDR $P$. aeruginosa strains, of which $48 \%$ had mucoid phenotypes: C/T appeared the most active antimicrobial, with an $86 \%$ susceptibility that was not influenced by treatment; $10 \%$ of isolates resulted intermediate, and $4 \%$ were resistant to $\mathrm{C} / \mathrm{T}$. Time-kill analyses of $\mathrm{C} / \mathrm{T}$ alone and in combination with tobramycin or amikacin against five $P$. aeruginosa isolates from four pediatric CF patients demonstrated that concentrations of at least $8 \times \mathrm{C} / \mathrm{T}$ MIC are required for an adequate killing (29). The synergistic activity of aminoglycoside combination, when the isolate was $\mathrm{C} / \mathrm{T}$ susceptible, was more pronounced with amikacin than with tobramycin (29). 


\section{C/T CLINICAL DATA IN ADULT PATIENTS WITH P. AERUGINOSA INFECTION}

The first data on efficacy and safety of $\mathrm{C} / \mathrm{T}$ in the adult population came from two phase 3 randomized clinical trials (RCTs), called, respectively, ASPECT-cIAI and ASPECT-cUTI, in which $\mathrm{C} / \mathrm{T}$ non-inferiority with respect to meropenem and levofloxacin allowed the formal approval of the investigational drug for the treatment of cIAIs and cUTIs $(30,31)$. A third RCT, ASPECT-NP, comparing C/T vs. meropenem for hospitalacquired bacterial pneumonia (HABP) or ventilator-associated bacterial pneumonia (VABP), was recently concluded and lead to the inclusion of severe respiratory infections within the labeled indications (32). Such registration trials included few patients infected with MDR bacteria, although this is the actual field where $\mathrm{C} / \mathrm{T}$ addresses an unmet medical need.

In real life, $\mathrm{C} / \mathrm{T}$ has been used for treating a broad spectrum of severe infections due to susceptible pathogens, including ESBLproducing Enterobacteriaceae (according to a carbapenemsparing strategy) and $P$. aeruginosa (33). However, observational studies reporting the use of $\mathrm{C} / \mathrm{T}$ for treating $\mathrm{MDR} P$. aeruginosa in adults consist of case series and case reports.

In a retrospective study involving 22 Italian hospitals, Bassetti et al. (34) described a wide adult population (101 patients) treated with $\mathrm{C} / \mathrm{T}$ for different $P$. aeruginosa infections, including nosocomial pneumonia (31.7\%), acute bacterial skin and skinstructure infection $(20.8 \%)$, cUTI (13.9\%), cIAI (12.9\%), bone infection (8.9\%), and primary bacteremia (5.9\%). Barely a half $(50.5 \%)$ of $P$. aeruginosa isolates were $\mathrm{XDR}$, with the majority resistant to at least one carbapenem. Overall clinical success was $83.2 \%$, but significantly lower rates were reported in patients with sepsis or under continuous renal replacement therapy. Ceftolozane-tazobactam was mainly used as secondline or later with a median duration of 14 days. In more than one-third of patients, it was concomitantly administered with other antipseudomonal agents, such as aminoglycosides, colistin, and carbapenems.

A more recent study analyzed 259 adults treated with $\mathrm{C} / \mathrm{T}$ for MDR Gram-negative infections; $P$. aeruginosa was the causative agent in the majority (91.1\%) of patients, and the most common infection source was the respiratory tract (35). Clinical failure was reported in $37.6 \%$ of cases and was independently related to hospital-acquired infection and higher Acute Physiology and Chronic Health Evaluation II score. Combination intravenous (IV) antibiotic therapy was used in $24.7 \%$ of patients, most commonly an aminoglycoside. Adjuvant therapy with inhalation tobramycin or colistin was administered in $29.4 \%$ of patients with a respiratory tract infection (RTI).

In general, the use of combination therapy for the management of infections caused by $P$. aeruginosa has been explored in vitro and in vivo with the objective of investigating the potential synergistic or additive effects of certain combinations of drugs with different mechanisms of action (36). Available data suggest that combination therapy may be beneficial for treating severe infections sustained by MDR Gram-negative bacteria in high-risk patients, such as those affected by $\mathrm{CF}$, whereas monotherapy may be enough for lower-risk patients (37). Combination therapy may be beneficial also to prevent the development of antimicrobial resistance (38). However, this is counterbalanced by the additional risk of toxicity (mainly kidney insufficiency) and by the poor pulmonary penetration and diminished antibacterial activity of aminoglycosides in the acidic pneumonic airways (35).

\section{C/T DOSAGE IN CF ADULT PATIENTS}

The approved C/T dosage in adults is $1.5 \mathrm{~g}$ IV every $8 \mathrm{~h}$ (q8h) for cUTIs and cIAIs, whereas a higher dose comprising $2 \mathrm{~g}$ of ceftolozane and $1 \mathrm{~g}$ of tazobactam $\mathrm{q} 8 \mathrm{~h}$ is recommended for treating either $\operatorname{HABP}$ or $\operatorname{VABP}(39,40)$.

Before formal approval, in clinical practice the high-dose regimen $\mathrm{C} / \mathrm{T}$ (9 $\mathrm{g}$ daily) had been already used in a large amount of adult patients with MDR Gram-negative bacterial infections, mostly with RTIs (35).

In patients with lower RTIs caused by MDR and XDR $P$. aeruginosa, higher MICs ( $>2 \mathrm{mg} / \mathrm{L}$ ) were found to be associated with lower efficacy of $\mathrm{C} / \mathrm{T}$ and higher 30 -day mortality $(P=$ 0.045 ) independently from the dosage used (41). However, it has been demonstrated that in patients receiving continuous infusion of $\mathrm{C} / \mathrm{T}$ the pharmacokinetic/pharmacodynamic (PK/PD) target is achieved even for strains with MICs equal to $8 \mathrm{mg} / \mathrm{L}$ (42).

The $3 \mathrm{~g}$ q8h RTIs dosage has been safely and successfully used in CF adults with pulmonary exacerbations $(2,43)$. Patients with CF have been reported to have altered PKs, in terms of larger volume of distribution, increased total body clearance of $\beta$-lactams, lower exposure, and shorter elimination half time; therefore, maximal dosages are often required to achieve adequate plasma and epithelial lining fluid concentrations of antimicrobials (44). Nevertheless, in $20 \mathrm{CF}$ patients, C/T clearance resulted similar to what was observed in non-CF adults, although the volume of the central compartment was lower (43). The results of the Monte Carlo simulation lead the authors to recommend the use of $3 \mathrm{~g} \mathrm{q} 8 \mathrm{~h}$ also for treating pulmonary $\mathrm{CF}$ exacerbations in adults: a $>90 \%$ probability of the PD target attainment exposure of $60 \%$ free time above the MIC ( $f$ T > MIC) was achieved at MICs up to 4 and $8 \mu \mathrm{g} / \mathrm{mL}$ with the $1.5-$ and 3 -g dosage, respectively (43). At present, whether C/T higher dosages, extended infusion regimens, or reduced dosing intervals are required in CF adults with pulmonary exacerbations has not been sorted out.

A continuous infusion regimen of $\mathrm{C} / \mathrm{T}$, associated to therapeutic drug monitoring to assess adequacy of exposure, was successful in a CF adult patient with augmented renal clearance (45).

\section{PHARMACOKINETIC AND CLINICAL DATA IN THE PEDIATRIC POPULATION}

Pharmacokinetic and safety of $\mathrm{C} / \mathrm{T}$ were evaluated in a phase I trial enrolling 37 neonates and children up to 17 years of age with Gram-negative infections (46-48). Single IV age-based doses, 
TABLE 1 | Characteristics and outcomes of five children with Pseudomonas aeruginosa infection treated with Ceftolozane/tazobactam.

\begin{tabular}{|c|c|c|c|c|c|c|c|c|c|c|}
\hline Author (year) & $\begin{array}{c}\text { Age } \\
\text { (years) }\end{array}$ & Sex & Type of infection & $\begin{array}{l}\text { Concomitant } \\
\text { disease(s) }\end{array}$ & C/T MIC & $\begin{array}{l}\mathrm{C} / \mathrm{T} \text { treatment } \\
\text { (daily dosage, } \\
\text { duration) }\end{array}$ & Ceftolozane $\mathrm{C}_{\min }$ & C/T-related AEs & $\begin{array}{l}\text { Concomitant } \\
\text { antimicrobials }\end{array}$ & Outcome \\
\hline \multirow[t]{2}{*}{ Aitken et al. (53) } & 9 & M & P. aeruginosa BSI & $\begin{array}{l}\text { Acute myeloid } \\
\text { leukemia }\end{array}$ & $6 \mu \mathrm{g} / \mathrm{mL}$ & $\begin{array}{l}50 \mathrm{mg} / \mathrm{kg} \mathrm{C} \text { every } \\
8 \mathrm{~h} \text { over a 3-h } \\
\text { infusion (first } \\
\text { treatment), } 3 \\
\text { weeks) }\end{array}$ & $5.2 \mu \mathrm{g} / \mathrm{mL}$ & None & $\begin{array}{l}\text { Tobramycin, } \\
\text { ciprofloxacin }\end{array}$ & $\begin{array}{l}\text { Recovered after a } \\
\text { first relapse }\end{array}$ \\
\hline & & & & & $8 \mu \mathrm{g} / \mathrm{mL}$ & $\begin{array}{l}40 \text { mg/kg C every } \\
6 \text { h over a 3-h } \\
\text { infusion (second } \\
\text { treatment), } \\
3 \text { weeks }\end{array}$ & $18.1 \mu \mathrm{g} / \mathrm{mL}$ & & & \\
\hline Zikri and Masri (54) & 14 & $\mathrm{~F}$ & $\begin{array}{l}\text { MDR } P \text {. aeruginosa } \\
\text { pneumonia }\end{array}$ & $\begin{array}{l}\text { Combined } \\
\text { immunodeficiency } \\
\text { syndrome }\end{array}$ & $3 \mu \mathrm{g} / \mathrm{mL}$ & $\begin{array}{l}1 \mathrm{~g}(\mathrm{C})+0,5 \mathrm{~g}(\mathrm{~T}) \\
\text { every } 8 \mathrm{~h}, \\
\text { corresponding to } \\
44 / 22 \mathrm{mg} / \mathrm{kg}(\mathrm{C} / \mathrm{T}) \\
\text { every } 8 \mathrm{~h}, \mathrm{NA}\end{array}$ & NA & None & Amikacin, colistin & Recovered \\
\hline Ang et al. (55) & 14 & $\mathrm{~F}$ & $\begin{array}{l}P \text {. aeruginosa } \\
\text { pulmonary } \\
\text { exacerbation }\end{array}$ & Cystic fibrosis & $\begin{array}{l}\text { Mucoid strain } \\
0.5 \mu \mathrm{g} / \mathrm{mL} \text {; non-m } \\
\text { ucoid strain MIC } \\
1 \mu \mathrm{g} / \mathrm{mL}\end{array}$ & $\begin{array}{l}1 \mathrm{~g}(\mathrm{C})+0,5 \mathrm{~g}(\mathrm{~T}) \\
\text { every } 8 \mathrm{~h}, \\
\text { corresponding to } \\
31.25 \mathrm{mg} / \mathrm{kg}(\mathrm{C}) \\
\text { every } 8 \mathrm{~h}, 14 \text { days }\end{array}$ & $1.2 \mu \mathrm{g} / \mathrm{mL}$ & None & Ciprofloxacin & Recovered \\
\hline $\begin{array}{l}\text { Martín-Cazaña } \\
\text { et al. (56) }\end{array}$ & 5 & M & $\begin{array}{l}P \text {. aeruginosa } \\
\text { endocarditis }\end{array}$ & $\begin{array}{l}\text { Complex } \\
\text { congenital heart } \\
\text { disease }\end{array}$ & $2 \mu \mathrm{g} / \mathrm{mL}$ & $\begin{array}{l}50 \mathrm{mg} / \mathrm{kg}(\mathrm{C}) \\
\text { every } 8 \mathrm{~h} \text { over 3-h } \\
\text { infusion, } 45 \text { days }\end{array}$ & $2.6 \mathrm{ng} / \mathrm{mL}$ & None & Tobramycin & Recovered \\
\hline Dinh et al. (57) & 3 & M & $\begin{array}{l}\text { XDR P. aeruginosa } \\
\text { vascular graft infection }\end{array}$ & Liver transplant & NA & $\begin{array}{l}1.5 \mathrm{~g}(\mathrm{C})+0.75 \mathrm{~g} \\
(\mathrm{~T}) / \text { day, } 57 \text { days }\end{array}$ & NA & $\begin{array}{l}\text { Clostridium difficile } \\
\text { infection }\end{array}$ & Colistin & Failure \\
\hline
\end{tabular}

C, ceftolozane; T, tazobactam; AEs, adverse events; M, male; F, female; BSI, bloodstream infection; MDR, multidrug resistant; NA, not available. 
ranging from 18 to $30 \mathrm{mg} / \mathrm{kg}$ up to $1.5 \mathrm{~g}$ of ceftolozane with a fixed 2:1 ratio of $\mathrm{C} / \mathrm{T}$, were well-tolerated and resulted in ceftolozane PK parameters generally comparable among various age groups of children older than 3 months. Patients $<3$ months of age had a lower clearance and a slightly higher volume of distribution of $\mathrm{C} / \mathrm{T}$ compared to older children, consistent with an immature renal function in this cohort and given that both products are cleared by the kidney.

Of note, the interim analysis led to the increase of $\mathrm{C} / \mathrm{T}$ dosage to $30 / 15 \mathrm{mg} / \mathrm{kg}$ in children aged $>3$ months to $<7$ years and to $20 / 10 \mathrm{mg} / \mathrm{kg}$ in neonates and infants $<3$ months of age.

Larson et al. (49) developed a population PK (popPK) model of $\mathrm{C} / \mathrm{T}$ integrating $\mathrm{PK}$ data from 12 adult clinical trials (healthy volunteers, volunteers with renal impairment, and patients with cUTIs o cIAIs) and the above mentioned phase I pediatric study. The popPK analysis showed that a twocompartment linear model with first-order elimination welldescribes the concentration vs. time profile of $\mathrm{C} / \mathrm{T}$, that renal function significantly affects $\mathrm{C} / \mathrm{T}$ clearance, and that body weight influences both C/T clearance and volume of distribution (49). The popPK model guided dose selection for two ongoing phase 2 trials evaluating $\mathrm{C} / \mathrm{T}$ for the treatment of cUTIs and cIAIs in children: $1.5 \mathrm{~g}$ q8h over a 1-h infusion for children 12 to $<18$ years old and $20 / 10 \mathrm{mg} / \mathrm{kg}$ q $8 \mathrm{~h}$ for children $<12$ years old $(50,51)$.

In the pediatric phase I trial, several children with $\mathrm{CF}$ were enrolled; an unpublished analysis of C/T PK using model-derived parameters showed no relevant differences between children with or without CF (52).

To date, five pediatric patients treated with C/T for MDR or XDR $P$. aeruginosa infection have been described; each child had serious underlying comorbidities (Table 1).

A therapeutic failure was recorded under $\mathrm{C} / \mathrm{T}$ treatment (57 days) in a liver transplant recipient with XDR $P$. aeruginosa vascular graft infection (57). On the other hand, $\mathrm{C} / \mathrm{T}$ was successfully used to treat bilateral pneumonia with septic shock in a girl with combined immunodeficiency syndrome, a bloodstream infection in a 9-year-old boy with relapsed/refractory acute myeloid leukemia, and an endocarditis in a child with congenital heart defect $(53,54,56)$. In all these patients, C/T was well-tolerated, even for prolonged treatments. Whenever performed, PK analysis demonstrated appropriate plasma levels of ceftolozane with respect to the MIC of the isolate.

One single case regarding the use of $\mathrm{C} / \mathrm{T}$ in pediatric patients with CF was retrieved in the literature (55). Ang et al. (55) described a 14-year-old girl with CF and MDR P. aeruginosa pulmonary exacerbations; notably after desensitization due to $\beta$-lactam allergy, she was treated with $\mathrm{C} / \mathrm{T}$ at a dosage of $1.5 \mathrm{~g}$ $\mathrm{q} 8 \mathrm{~h}$ over a 1 - $\mathrm{h}$ infusion, which was equivalent, in milligrams per kilograms, to the adult $3 \mathrm{~g}$ q8h HAP dosage. A PK study was performed at steady state, and $\mathrm{PK}$ parameters of $\mathrm{C} / \mathrm{T}$ were then modeled to simulate a variety of $\mathrm{C} / \mathrm{T}$ dosing regimens, such as $1.5 \mathrm{~g} \mathrm{q} 8 \mathrm{~h}, 1.5 \mathrm{~g} \mathrm{q} 6 \mathrm{~h}$, and $3 \mathrm{~g} \mathrm{q} 8 \mathrm{~h}$, each given as 1 - or 3 -h infusion. All regimens exceeded the $\mathrm{PD}$ target $f \mathrm{~T}>\mathrm{MIC}$ of $40 \%$, but authors postulated that the use of higher dosages, more frequent administrations, and/or prolonged infusion of $\mathrm{C} / \mathrm{T}$ might be necessary to guarantee $\mathrm{PD}$ optimization when $P$. aeruginosa $\mathrm{MIC}$ for $\mathrm{C} / \mathrm{T}$ is 4 to $8 \mu \mathrm{g} / \mathrm{mL}$.

\section{CONCLUSIONS}

To date, C/T appears one of the most active drugs against $P$. aeruginosa, representing an important new therapeutic option for difficult-to-treat infections due to MDR strains, also outside approved indications (4).

The favorable safety profile of tazobactam in children is well-known because of the consolidate use of the association with piperacillin in hospitalized pediatric patients. Ceftolozane appears to be well-tolerated in adults even at high dosages; according to phase I clinical trials results in children, that is expected to occur also in the pediatric population where other IV cephalosporins are routinely and safely used. All these properties make $\mathrm{C} / \mathrm{T}$ a possible therapeutic strategy to treat children with CF pulmonary exacerbations due to $\operatorname{MDR} P$. aeruginosa $(58,59)$. Awaiting for more robust data in the pediatric population and inferring from the real-life experience in adults, we suggest using $\mathrm{C} / \mathrm{T}$ in combination with other antimicrobial agents, such as aminoglycosides or colistin, to treat serious infections, in order to prevent resistance selection and to obtain an eventual synergistic effect.

However, a few considerations are due. First, it is debated whether susceptibility patterns should guide or not the selection of antibiotics to treat CF exacerbations, as some data show that in vitro $P$. aeruginosa susceptibility patterns do not predict clinical response (60). Secondly, limiting the use of new antimicrobials is a crucial element of the antimicrobial stewardship program; therefore, $\mathrm{C} / \mathrm{T}$ prescription should be prerogative of infectious diseases specialists and limited to selected cases where other therapeutic options are unfeasible, aiming at preventing drug overuse and rapid selection of microbial resistance. Finally, the proper $\mathrm{C} / \mathrm{T}$ dosing regimen has not yet been defined in $\mathrm{CF}$ patients and especially in children. Given the available data from clinical studies and from popPK models, it may be inferred that in CF children with pulmonary infections and a normal renal function a ceftolozane dose of at least $30-40 \mathrm{mg} / \mathrm{kg} \mathrm{q} 8 \mathrm{~h}$ (according to age) is required. However, given that CF patients may have altered drugs' pharmacokinetics, additional strategies, such as prolonged infusions or q6h dosing, may be necessary to guarantee adequate drug exposure, especially if the MIC of the causative organism is unfavorable. Additional clinical and PK studies on $\mathrm{C} / \mathrm{T}$ use in children with $\mathrm{CF}$ are warranted before any definite recommendation could be made.

\section{AUTHOR CONTRIBUTIONS}

All authors significantly contributed to the present manuscript. SG designed the study, reviewed the literature and wrote the manuscript. EA, ES, GP, CS, and EB reviewed the literature, corrected the manuscript and edited English style. 


\section{REFERENCES}

1. Lyczak JB, Cannon CL, Pier GB. Lung infections associated with cystic fibrosis. Clin Microbiol Rev. (2002)15:194-222. doi: 10.1128/CMR.15.2.194-222.2002

2. Vickery SB, McClain D, Wargo KA. Successful use of ceftolozanetazobactam to treat a pulmonary exacerbation of cystic fibrosis caused by multidrug-resistant Pseudomonas aeruginosa. Pharmacotherapy. (2016) 36:e154-9. doi: 10.1002/phar.1825

3. Stokem K, Zuckerman JB, Nicolau DP, Wungwattana M, Sears EH. Use of ceftolozane-tazobactam in a cystic fibrosis patient with multidrug-resistant pseudomonas infection and renal insufficiency. Respir Med Case Rep. (2017) 28:8-9. doi: 10.1016/j.rmcr.2017.10.012

4. Maraolo AE, Mazzitelli M, Trecarichi EM, Buonomo AR, Torti C, Gentile I. Ceftolozane/tazobactam for difficult-to-treat Pseudomonas aeruginosa infections: a systematic review about its efficacy and safety for off-label indications. Int J Antimicrob Agents. (2020) 7:105891. doi: 10.1016/j.ijantimicag.2020.105891

5. Murano K, Yamanaka T, Toda A, Ohki H, Okuda S, Kawabata K, et al. Structural requirements for the stability of novel cephalosporins to AmpC beta-lactamase based on 3D-structure. Bioorg Med Chem. (2008) 16:226175. doi: 10.1016/j.bmc.2007.11.074

6. Moya B, Zamorano L, Juan C, Ge Y, Oliver A. Affinity of the new cephalosporin CXA-101 to penicillin-binding proteins of Pseudomonas aeruginosa. Antimicrob Agents Chemother. (2010) 54:3933-7. doi: 10.1128/AAC.00296-10

7. Vanscoy B, Mendes RE, McCauley J, Bhavnani SM, Bulik CC, Okusanya OO, et al. Pharmacological basis of $\beta$-lactamase inhibitor therapeutics: tazobactam in combination with cefolozane. Antimicrob Agents Chemother. (2013) 57:5924-31. doi: 10.1128/AAC.00656-13

8. Zhanel GG, Chung P, Adam H, Zelenitsky S, Denisuik A, Schweizer F, et al. Ceftolozane/tazobactam: a novel cephalosporin/beta-lactamase inhibitor combination with activity against multidrug-resistant gram-negative bacilli. Drugs. (2014) 74:31-51. doi: 10.1007/s40265-013-0168-2

9. Miller B, Hershberger E, Benziger D, Trinh M, Friedland I. Pharmacokinetics and safety of intravenous Ceftolozane/tazobactam in healthy adult subjects following single and multiple ascending doses. Antimicrob Agents Chemother. (2012) 56:3086-91. doi: 10.1128/AAC.06349-11

10. Zamorano L, Juan C, Fernandez-Olmos A, Ge Y, Canton R, Oliver A. Activity of the new cephalosporin CXA-101 (FR264205) against Pseudomonas aeruginosa isolates from chronically-infected cystic fibrosis patients. Clin Microbiol Infect. (2010) 16:1482-7. doi: 10.1111/j.1469-0691.2010.03130.x

11. Grupper M, Sutherland C, Nicolau DP. Multicenter evaluation of ceftazidime-avibactam and ceftolozane-tazobactam inhibitory activity against meropenem-nonsusceptible Pseudomonas aeruginosa from blood, respiratory tract, and wounds. Antimicrob Agents Chemother. (2017) 61:e00875-17. doi: 10.1128/AAC.00875-17

12. Shortridge D, Pfaller MA, Streit JM, Flamm RK. Antimicrobial activity of ceftolozane-tazobactam tested against contemporary (2015-2017) P. aeruginosa isolates from a global surveillance program. J Glob Antimicrob Resist. (2019) 21:60-4. doi: 10.1016/j.jgar.2019.10.009

13. Shortridge D, Duncan LR, Pfaller MA, Flamm RK. Activity of ceftolozanetazobactam and comparators when tested against Gram-negative isolates collected from paediatric patients in the USA and Europe between 2012 and 2016 as part of a global surveillance programme. Int J Antimicrob Agents. (2019) 53:637-43. doi: 10.1016/j.ijantimicag.2019.01.015

14. Shortridge D, Pfaller MA, Arends SJ, Raddatz J, DePestel DD, Flamm RK. Comparison of the in vitro susceptibility of ceftolozane-tazobactam with the cumulative susceptibility rates of standard antibiotic combinations when tested against pseudomonas aeruginosa from ICU patients with bloodstream infections or pneumonia. Open Forum Infect Dis. (2019) 6:ofz240. doi: 10.1093/ofid/ofz240

15. Mirza HC, Hortaç E, Koçak AA, Demirkaya MH, Yayla B, Güçlü AÜ, et al. In vitro activity of ceftolozane-tazobactam and ceftazidime-avibactam against clinical isolates of meropenem-non-susceptible pseudomonas aeruginosa: a two-center study. J Glob Antimicrob Resist. (2019) 20:334-8. doi: 10.1016/j.jgar.2019.09.016

16. Humphries RM, Hindler JA, Wong-Beringer A, Miller SA. Activity of ceftolozane-tazobactam and ceftazidime-avibactam against beta-lactamresistant Pseudomonas aeruginosa isolates. Antimicrob Agents Chemother. (2017) 61:e01858-17. doi: 10.1128/AAC.01858-17
17. Giani T, Arena F, Pollini S, Di Pilato V, D’Andrea MM, Henrici De Angelis L, et al. Italian nationwide survey on Pseudomonas aeruginosa from invasive infections: activity of Ceftolozane/tazobactam and comparators, and molecular epidemiology of carbapenemase producers. I Antimicrob Chemother. (2018) 73:664-71. doi: 10.1093/jac/dkx453

18. Barnes MD, Taracila MA, Rutter JD, Bethel CR, Galdadas I, Hujer $\mathrm{AM}$, et al. Deciphering the evolution of cephalosporin resistance to ceftolozane-tazobactam in pseudomonas aeruginosa. mBio. (2018) 9:e0208518. doi: $10.1128 / \mathrm{mBio} .02085-18$

19. Haidar G, Philips NJ, Shields RK, Snyder D, Cheng S, Potoski BA, et al. Ceftolozane-tazobactam for the treatment of multidrug-resistant pseudomonas aeruginosa infections: clinical effectiveness and evolution of resistance. Clin Infect Dis. (2017) 65:110-20. doi: 10.1093/cid/ cix182

20. Zamudio R, Hijazi K, Joshi C, Aitken E, Oggioni MR, Gould IM. Phylogenetic analysis of resistance to ceftazidime/avibactam, Ceftolozane/tazobactam and carbapenems in piperacillin/tazobactam-resistant Pseudomonas aeruginosa from cystic fibrosis patients. Int J Antimicrob Agents. (2019) 53:77480. doi: 10.1016/j.ijantimicag.2019.02.022

21. Skoglund E, Abodakpi H, Rios R, Diaz L, De La Cadena E, Dinh AQ, et al. In vivo resistance to Ceftolozane/tazobactam in pseudomonas aeruginosa arising by AmpC- and non-AmpC-mediated pathways. Case Rep Infect Dis. (2018) 2018:9095203. doi: 10.1155/2018/9095203

22. Rac H, Stover KR, Wagner JL, King ST, Warnock HD, Barber KE. Timekill analysis of Ceftolozane/tazobactam efficacy against mucoid Pseudomonas aeruginosa strains from cystic fibrosis patients. Infect Dis Ther. (2017) 6:50713. doi: $10.1007 / s 40121-017-0176-8$

23. Livermore DM, Mushtaq S, Ge Y, Warner M. Activity of cephalosporin CXA-101 (FR264205) against Pseudomonas aeruginosa and Burkholderia cepacia group strains and isolates. Int J Antimicrob Agents. (2009) 34:4026. doi: 10.1016/j.ijantimicag.2009.03.021

24. Forrester JB, Steed LL, Santevecchi BA, Flume P, Palmer-Long GE, Bosso JA. In vitro activity of Ceftolozane/tazobactam vs nonfermenting, gram-negative cystic fibrosis isolates. Open Forum Infect Dis. (2018) 5:ofy158. doi: 10.1093/ofid/ofy158

25. Gramegna A, Millar BC, Blasi F, Elborn JS, Downey DG, Moore JE. In vitro antimicrobial activity of Ceftolozane/tazobactam against Pseudomonas aeruginosa and other non-fermenting Gram-negative bacteria in adults with cystic fibrosis. J Glob Antimicrob Resist. (2018) 14:2247. doi: 10.1016/j.jgar.2018.03.002

26. Finklea JD, Hollaway R, Lowe K, Lee F, Le J, Jain R. Ceftolozane/tazobactam sensitivity patterns in Pseudomonas aeruginosa isolates recovered from sputum of cystic fibrosis patients. Diagn Microbiol Infect Dis. (2018) 92:757. doi: $10.1016 /$ j.diagmicrobio.2018.05.002

27. Gherardi G, Linardos G, Pompilio A, Fiscarelli E, Di Bonaventura G. Evaluation of in vitro activity of Ceftolozane-tazobactam compared to other antimicrobial agents against Pseudomonas aeruginosa isolates from cystic fibrosis patients. Diagn Microbiol Infect Dis. (2019) 94:297303. doi: 10.1016/j.diagmicrobio.2019.01.012

28. Kuti JL, Pettit RS, Neu N, Cies JJ, Lapin C, Muhlebach MS, et al. Microbiological activity of Ceftolozane/tazobactam, ceftazidime, meropenem, and piperacillin/tazobactam against Pseudomonas aeruginosa isolated from children with cystic fibrosis. Diagn Microbiol Infect Dis. (2015) 83:535. doi: 10.1016/j.diagmicrobio.2015.04.012

29. Dassner M, Sutherland C, Girotto, Nicolau DP. In vitro activity of Ceftolozane/tazobactam alone or with an aminoglycoside against multi-drugresistant Pseudomonas aeruginosa from pediatric cystic fibrosis patients. Infect Dis Ther. (2017) 6:129-36. doi: 10.1007/s40121-016-0141-y

30. Solomkin J, Hershberger E, Miller B, Popejoy M, Friedland I, Steenbergen J, et al. Ceftolozane/tazobactam plus metronidazole for complicated intraabdominal infections in an era of multidrug resistance: results from a randomized, double-blind, phase 3 trial (ASPECT-cIAI). Clin Infect Dis. (2015) 60:1462-71. doi: 10.1093/cid/civ097

31. Wagenlehner FM, Umeh O, Steenbergen J, Yuan G, Darouiche RO. Ceftolozane-tazobactam compared with levofloxacin in the treatment of complicated urinary-tract infections, including pyelonephritis: a randomised, double-blind, phase 3 trial (ASPECT-cUTI). Lancet. (2015) 385:194956. doi: 10.1016/S0140-6736(14)62220-0

32. Kollef MH, Nováček M, Kivistik Ü, Réa-Neto Á, Shime N, MartinLoeches I, et al. Ceftolozane-tazobactam versus meropenem for treatment 
of nosocomial pneumonia (ASPECT-NP): a randomised, controlled, doubleblind, phase 3, non-inferiority trial. Lancet Infect Dis. (2019) 19:1299311. doi: 10.1016/S1473-3099(19)30403-7

33. Giacobbe DR, Bassetti M, De Rosa FG, Del Bono V, Grossi PA, Menichetti F, et al. Ceftolozane/tazobactam: place in therapy. Expert Rev Anti Infect Ther. (2018) 16:307-20. doi: 10.1080/14787210.2018.1447381

34. Bassetti M, Castaldo N, Cattelan A, Mussini C, Righi E, Tascini C, et al. Ceftolozane/tazobactam for the treatment of serious Pseudomonas aeruginosa infections: a multicentre nationwide clinical experience. Int J Antimicrob Agents. (2019) 53:408-15. doi: 10.1016/j.ijantimicag.2018.11.001

35. Jorgensen SCJ, Trinh TD, Zasowski EJ, Lagnf AM, Simon SP, Bhatia S, et al. Real-world experience with ceftolozane-tazobactam for multidrug-resistant gram-negative bacterial infections. Antimicrob Agents Chemother. (2020) 13:AAC.02291-19. doi: 10.1128/AAC.02291-19

36. Olsson A, Wistrand-Yuen P, Nielsen EI, Friberg LE, Sandegren L, Lagerbäck P, et al. Evaluation of the efficacy of antibiotic combinations against multidrugresistant Pseudomonas aeruginosa in automated time-lapse microscopy and static time-kill experiments. Antimicrob Agents Chemother. (2020) 16:AAC.02111-19. doi: 10.1128/AAC.02111-19

37. Rodríguez-Baño J, Gutiérrez-Gutiérrez B, Machuca I, Pascual A. Treatment of infections caused by extended-spectrum-beta-lactamase-, AmpC-, and carbapenemase-producing enterobacteriaceae. Clin Microbiol Rev. (2018) 31:e00079-17. doi: 10.1128/CMR.00079-17

38. Idowu T, Zhanel GG, Schweizer F. A dimer, but not monomer, of tobramycin potentiates ceftolozane against multidrug-resistant and extensively drug-resistant Pseudomonas aeruginosa and delays resistance development. Antimicrob Agents Chemother. (2020) 64:e02055-19. doi: 10.1128/AAC.02055-19

39. European Medicines Agency. Human Medicine European Public Assessment Report (EPAR): Zerbaxa. Available online at: https://www.ema.europa.eu/en/ medicines/human/EPAR/zerbaxa (accessed February 06, 2020).

40. Xiao AJ, Miller BW, Huntington JA, Nicolau DP. Ceftolozane/tazobactam pharmacokinetic/pharmacodynamic-derived dose justification for phase 3 studies in patients with nosocomial pneumonia. J Clin Pharmacol. (2016) 56:56-66. doi: 10.1002/jcph.566

41. Rodríguez-Núñez O, Periañez-Parraga L, Oliver A, Munita JM, Boté A, Gasch $\mathrm{O}$, et al. Higher MICs $(>2 \mathrm{mg} / \mathrm{L}$ ) predict 30 -day mortality in patients with lower respiratory tract infections caused by multidrug- and extensively drugresistant Pseudomonas aeruginosa treated with Ceftolozane/tazobactam. Open Forum Infect Dis. (2019) 6:ofz416. doi: 10.1093/ofid/ofz416

42. Pilmis B, Petitjean G, Lesprit P, Lafaurie M, El Helali N, Le Monnier $\mathrm{A}$, et al. Continuous infusion of Ceftolozane/tazobactam is associated with a higher probability of target attainment in patients infected with Pseudomonas aeruginosa. Eur J Clin Microbiol Infect Dis. (2019) 38:145761. doi: 10.1007/s10096-019-03573-4

43. Monogue, ML, Pettit RS, Muhlebach M, Cies JJ, Nicolau DP, Kuti JL. Population pharmacokinetics and safety of Ceftolozanetazobactam in adult cystic fibrosis patients admitted with acute pulmonary exacerbation. Antimicrob Agents Chemother. (2016) 60:6578-84. doi: 10.1128/AAC.01566-16

44. De Groot R, Smith AL. Antibiotic pharmacokinetics in cystic fibrosis. differences and clinical significance. Clin Pharmacokinet. (1987) 13:22853. doi: 10.2165/00003088-198713040-00002

45. Davis ES, Ham J, Hucks J, Gould A, Foster R, Ann Justo J, et al. Use of continuous infusion ceftolozane-tazobactam with therapeutic drug monitoring in a patient with cystic fibrosis. Am J Health Syst Pharm. (2019) 76:501-4. doi: 10.1093/ajhp/zxz011

46. European Medicines Agency. Assessment Report for Paediatric Studies Submitted According to Article 46 of the Regulation (EC) No 1901/2006. CXAPEDS-13-08. Open-Label, Single Dose Study to Evaluate the Pharmacokinetics and Safety of Ceftolozane/tazobactam in Children (0-18 years) With Proven or Suspected Gram-Negative Infection Receiving Standard Antibiotic Therapy. Available online at: https://www.ema.europa.eu/en/documents/variationreport/zerbaxa-h-c-3772-p46-002-epar-assessment-report_en.pdf (accessed February 06, 2020).

47. Bradley JS, Ang JY, Arrieta AC, Larson KB, Rizk ML, Caro L, et al. Pharmacokinetics and safety of single intravenous doses of Ceftolozane/tazobactam in children with proven or suspected Gram-negative infection. Pediatr Infect Dis J. (2018) 37:1130-6. doi: 10.1097/INF.0000000000002170

48. Ang JY, Arrieta A, Bradley JS, Zhang Z, Yu B, Rizk ML, et al. Ceftolozane/tazobactam in neonates and young infants: the challenges of collecting pharmacokinetics and safety data in this vulnerable patient population. Am J Perinatol. (2020) 7. doi: 10.1055/s-0039-3402719

49. Larson KB, Patel YT, Willavize S, Bradley JS, Rhee EG, Caro L et al. Ceftolozane-tazobactam population pharmacokinetics and dose selection for further clinical evaluation in pediatric patients with complicated urinary tract or complicated intra-abdominal infections. Antimicrob Agents Chemother. (2019) 63:e02578-18. doi: 10.1128/AAC.02578-18

50. ClinicalTrails.gov. MK-7625A Versus Meropenem in Pediatric Participants With Complicated Urinary Tract Infection (cUTI) (MK-7625A-034). Available online at: https://clinicaltrials.gov/ct2/show/NCT03230838 (accessed February 06, 2020).

51. ClinicalTrails.gov. MK-7625A Plus Metronidazole Versus Meropenem in Pediatric Participants With Complicated Intra-Abdominal Infection (cIAI) (MK-7625A-035). Available online at: https://clinicaltrials.gov/ct2/show/ NCT03217136 (accessed February 06, 2020).

52. Larson KB, Bradley J, Arrieta A, Yang S, Yu B, Johnson MG, et al. Plasma pharmacokinetics of Ceftolozane/tazobactam in pediatric subjects with cystic fibrosis. Poster 825. Paper presented at: IDWeek 2017; Oct 4-8, 2017, San Diego, CA (2017). doi: 10.1093/ofid/ofx163.679

53. Aitken SL, Kontoyiannis DP, DePombo AM, Bhatti MM, Tverdek FP, Gettys SC, et al. Use of Ceftolozane/tazobactam in the treatment of multidrug-resistant Pseudomonas aeruginosa bloodstream Infection in a pediatric leukemia patient. Pediatr Infect Dis J. (2016) 35:10402. doi: $10.1097 / \mathrm{INF} .0000000000001228$

54. Zikri A, El Masri K. Use of Ceftolozane/tazobactam for the treatment of multidrug-resistant Pseudomonas aeruginosa pneumonia in a pediatric patient with combined immunodeficiency (CID): a case report from a tertiary hospital in Saudi Arabia. Antibiotics. (2019) 8:E67. doi: $10.3390 /$ antibiotics 8020067

55. Ang JY, Abdel-Haq N, Zhu F, Thabit AK, Nicolau DP, Satlin MJ, et al. Multidrug-resistant Pseudomonas aeruginosa infection in a child with cystic fibrosis. Antimicrob Agents Chemother. (2016) 60:5627-30. doi: 10.1128/AAC.00705-16

56. Martín-Cazaña M, Grau S, Epalza C, Brañas P, Flores M, Olmedilla M, et al. Successful ceftolozane-tazobactam rescue therapy in a child with endocarditis caused by multidrug-resistant Pseudomonas aeruginosa. J Paediatr Child Health. (2019) 55:985-7. doi: 10.1111/jpc.14388

57. Dinh A, Wyplosz B, Kernéis S, Lebeaux D, Bouchand F, Duran C, et al. Use of Ceftolozane/tazobactam as salvage therapy for infections due to extensively drug-resistant Pseudomonas aeruginosa. Int J Antimicrob Agents. (2017) 49:782-3. doi: 10.1016/j.ijantimicag.2017.04.001

58. Tamma SM, Hsu AJ, Tamma PD. Prescribing Ceftolozane/tazobactam for pediatric patients: current status and future implications. Paediatr Drugs. (2016) 18:1-11. doi: 10.1007/s40272-015-0157-x

59. Rodriguez BA, Girotto JE, Nicolau DP. Ceftazidime/avibactam and Ceftolozane/tazobactam: novel therapy for multidrug resistant Gram negative infections in children. Curr Pediatr Rev. (2018) 14:97-109. doi: 10.2174/1573396314666180308150908

60. Smith AL, Fiel SB, Mayer-Hamblett N, Ramsey B, Burns JL. Susceptibility testing of Pseudomonas aeruginosa isolates and clinical response to parenteral antibiotic administration: lack of association in cystic fibrosis. Chest. (2003) 123:1495-502. doi: 10.1378/chest.123.5.1495

Conflict of Interest: The authors declare that the research was conducted in the absence of any commercial or financial relationships that could be construed as a potential conflict of interest.

Copyright (๑) 2020 Garazzino, Altieri, Silvestro, Pruccoli, Scolfaro and Bignamini. This is an open-access article distributed under the terms of the Creative Commons Attribution License (CC BY). The use, distribution or reproduction in other forums is permitted, provided the original author(s) and the copyright owner(s) are credited and that the original publication in this journal is cited, in accordance with accepted academic practice. No use, distribution or reproduction is permitted which does not comply with these terms. 